\title{
Take-over expectation and criticality in Level 3 automated driving: a test track study on take-over behavior in semi-trucks
}

\author{
Alexander Lotz $^{1,2} \cdot$ Nele Russwinkel $^{2} \cdot$ Enrico Wohlfarth $^{1}$ \\ Received: 27 November 2019 / Accepted: 21 February 2020 / Published online: 4 March 2020 \\ (c) The Author(s) 2020
}

\begin{abstract}
With the introduction of advanced driving assistance systems managing longitudinal and lateral control, conditional automated driving is seemingly in near future of series vehicles. While take-over behavior in the passenger car context has been investigated intensively in recent years, publications on semi-trucks with professional drivers are sparse. The effects influencing expert drivers during take-overs in this context lack thorough investigation and are required to design systems that facilitate safe take-overs. While multiple findings seem to cohere in passenger cars and semi-trucks, these findings rely on simulated studies without taking environments as found in the real world into account. A test track study was conducted, simulating highway driving with 27 professional non-affiliated truck drivers. The participants drove an automated Level 3 semi-truck while a non-driving-related task was available. Multiple time critical take-over situations were initiated during the drives to investigate four main objectives regarding driver behavior. (1) With these results, comparison of reaction times and behavior can be drawn to previous simulator studies. The effect of situation criticality (2) and training (3) of take-over situations is investigated. (4) The influence of warning expectation on driver behavior is explored. Results obtained displayed very quick time to hands on steering and time to first reaction all under $2.4 \mathrm{~s}$. Highly critical situations generate very quick reaction times $\mathrm{M}=0.81 \mathrm{~s}$, while the manipulation of expectancy yielded no significant variation in reaction times. These reaction times serve as a reference of what can be expected from drivers under optimal take-over conditions, with quick reactions at high speed in critical situations.
\end{abstract}

Keywords Conditional automated driving · Truck drivers · Driver take-over · Test-track study $\cdot$ Warning expectancy

\section{Introduction}

The term 'automated driving' has become a global discussion point in recent years, with political and social interests rising to develop vehicles enabling automation. While the progress has been significant within the past decade, complete automation of the driving task has not yet been achieved. Of late, new assistance systems are entering the market to support drivers in restricted scenarios such as Audi's traffic jam pilot (Audi 2017), Tesla's Autopilot

Alexander Lotz

rene_alexander.lotz@daimler.com

Nele Russwinkel

nele.russwinkel@tu-berlin.de

Daimler Truck AG, Stuttgart, Germany

2 Technische Universität Berlin, Marchstr. 23, Sekr. MAR 3-2, 10587 Berlin, Germany
(Tesla 2019) and the Mercedes Active Drive Assist for trucks (Daimler 2018). These systems rank as Level 2 partial automation and Level 3 conditional automated driving (SAE J3016 2018). Especially for Level 3, the difficulty of transitions between machine and driver is an ongoing research field, in which the system reaches limits and the driver needs to regain control of the vehicle in short timeframes (Young et al. 2007). Research within the field of automation transitions has shown that human capabilities can deteriorate due to task switching (Bainbridge 1983; Wylie et al. 2000) and a lack of situation awareness (Endsley 1995; Young et al. 2002). These effects also apply to advanced assistance systems in vehicles (Brookhuis et al. 2001; de Winter et al. 2014). If these theoretical constructs apply to the vehicles with advanced driver assistance systems, the question that is at the core of ongoing research is: how long do drivers require to regain control of vehicles safely (Gold et al. 2013)? 
The truck context does not contain the amount of publications as the passenger car context does for Level 3, as studies of take-over are often limited to instances without high time-pressure (Zhang et al. 2017). The effect of learning take-over situations (Lotz et al. 2019b), the influence of accustoming to a new automation function in experimental contexts and reacting to a new warning are influcences that have been investigated sporadicly in recent years (Kantowitz et al. 2009) and will be the main topic of the present study. Recent research by the ADAS\&ME project also addressed the specific issue of developing new driver monitoring systems to adjust human-machine interface content in the truck on the basis of driver needs (Axelson et al. 2018). This is important as most participants engage with the different automation functions for the first time in published research and in most studies only a handful of take-over situations are presented. Distinguishing underlying human capabilities that can or cannot adjust over time is paramount.

The aims of the present study are to investigate the behavior of semi-truck drivers in a prototypic vehicle in quasi real-world Level 3 automation on a test track. This will allow insight into driver behavior outside of simulated environments and possibly generate other results as previously determined. Different take-over situations will be investigated that vary in criticality to determine possible differences in driver behavior at take-over when a nondriving-related task (NDRT) is performed. The occasion of these take-overs will also be controlled, to investigate the effect of take-over expectancy. The following introductory sections focus on the current state of research of reaction times in critical take-over situation (Sect. 1.1), the effect of expected warnings (Sect. 1.2), the resulting aims of the study (Sect. 1.3), the definition of reaction times (Sect. 1.4) and hypotheses (Sect. 1.5).

\subsection{Reaction times in critical take-over situations}

Multiple studies have investigated reaction times in recent years, primarily in fixed and moving-base simulators (McDonald et al. 2019). Results indicate a large variation in reaction times ranging between 3 to $8 \mathrm{~s}$ according to Vogelpohl et al. (2016) and with an average reaction time until control is regained of $\mathrm{M}=2.96 \mathrm{~s}(\mathrm{SD}=1.96 \mathrm{~s})$ (Eriksson et al. 2017). As pointed out rightly by Zeeb et al. (2015), it does not seem as though reaction times are comparable due to the large variance in influencing factors that have been categorized into clusters by Vogelpohl et al. (2016): driver, environmental, vehicle and human-machine interaction factors. All of these studies mentioned were conducted within the passenger car context. A study of time critical take-overs during Level 3 driving in the truck context provided dis-

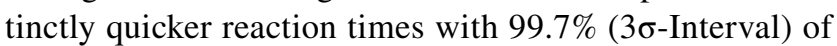
755 take-overs ranging between $0 \mathrm{~s}$ and $2.82 \mathrm{~s}$ (Lotz et al. 2019b). A possible explanation for these quick reaction times could be that within the truck context drivers are professionals, with far more experience controlling a vehicle, higher mileage, and daily repetition. Surprising critical takeover situations seem to reduce the reaction times also in the car context, as Diederichs et al. (2015) determine a reduction of 200 ms compared to expected take-overs. Previous work also investigated the possibility of predicting reaction times based on vehicle sensor data and a driver monitoring system (Lotz et al. 2019a). Limited predictability was achieved due to restricted data and low variance between prediction classes. A comparison study between the passenger car context and truck context investigating the difference in reactions has not been conducted to the best of the authors' knowledge. The detailed analysis of current publications also presents the difficulty of comparability of results, as experimental design and measures vary throughout all studies.

\subsection{Expected warnings and impact of trained transitions}

Research on advanced driver assistance systems of Level 2 (SAE J3016 2018) has shown that reaction times to start a motoric response is influenced by the expectation of an event occurring (Ruscio et al. 2015). However, while an unexpected situation arose in the abovementioned experimental real-life study, differences in criticality were not investigated. In addition, repetition of unforeseen events has thus far not been conducted, eliminating the possibility of observing learning of such situations (Kantowitz et al. 2009). Melcher et al. (2015) investigate an identical take-over situation while varying integration of a NDRT and automated braking. Prior learning of requests to intervene (RtI) has displayed positive effects on take-over performance. Additionally, the trust in automation seems to increase after an adequate stage in which drivers can accustom to a new function (Hergeth et al. 2016). Further research on false warnings has also shown that false warnings can affect subsequent reactions negatively (Lees et al. 2007). Therefore, an unanswered research question that arises is 'how learning of expected situations, not warnings, and the criticality of these take-overs may affect reaction times'? We thereby differentiate training from expectation. While we define the expectancy towards a takeover situation as the current state of the driver anticipating a take-over situation will arise within a short timeframe. This assumption by the driver is formed based on the surrounding of the vehicle, explicitly the approaching towards a steep curve in this study as described in Sect. 2.2. The opposing construct of training is the effect of improving take-over procedure through learning. While this study entails aspects of task switching and the current identification of situation awareness, these constructs will not be measured explicitly. 


\subsection{Scope of study}

The scope of the present study can be categorized into two main aspects.

1. A test-track study in a prototype vehicle providing the possibility of Level 3 automation with critical take-overs is investigated. By allowing participants to drive on a high-speed oval test-track with traffic, highly realistic highway scenarios are investigated with a prototypic vehicle rather than utilizing a simulator. This allows a comparison to previous simulator results regarding driver behavior for critical take-over situations for truck drivers. Additionally, possible shortcomings of simulator studies such as motion sickness and driving comfort as mentioned by Bellem et al. (2016) can be largely disregarded for the results of this study. Finally, traffic on the test track increases comparability to real-world driving on highways, as driver's are inclined to observe their surroundings during automation due to real rather than simulated vehicles. This generates important behavioral data regarding real-world take-over reactions. Due to safety regulations on the test track, no obstacles could be tossed in front of the vehicles at such high velocities with surrounding vehicles. Criticality, therefore, was induced through fictive malfunction of the automation function, i.e., by prompting a lateral steering swerve maneuver.

2. The test scenario intends to display two different takeover warnings throughout the drive resulting in three different take-over situation types. While all warning types are introduced in a preparatory tutorial phase, only the take-over type with the lowest criticality, in which these warnings will be initiated, is trained. This will lead to a discrepancy between learned behavior for different warnings and the current take-over situation witnessed. It is to be expected that this discrepancy causes differences in reaction times as explained in Sect. 2.2.5 and to adjust due to learning throughout the drives.

\subsection{Reaction time definition}

The reaction times collected within this study are defined in accordance with the work of Damböck (2013). Common take-over quality measures such as lateral variance in trajectory after take-over will not be reported, as precise localization was not possible in the prototype vehicle.

Time to eyes on road (TTEoR): the time from the beginning of the auditory and visual warning until the first fixation is started within the windscreen area of interest. This serves as a measure for cognitive processing and visual reaction.
Time to hands on steering (TTHoS): the time is defined from the beginning of the auditory and visual warning until hands touch the steering wheel for the first time. The measure expresses the motoric reaction time needed for the driver to regain the possibility of intervening in the lateral control of the vehicle.

Time to first reaction (TTFR): two thresholds are monitored to define the minimal reaction time measure. The minimum of the time required for pressing the ac-/decelerator pedal more than $5 \%$ or applying more than $1 \mathrm{Nm}$ at the steering wheel defines the TTFR. The metric allows for the interpretation of the time required by a driver to form a situation awareness and plan a route to circumvent possible obstacles in the trajectory of a vehicle.

\subsection{Hypotheses}

Based on the aims of the study in Sect.1.3, the following hypotheses are generated. While the data entail far more information, the study aims are reduced to the following four hypotheses.

1. Take-over situations of higher criticality will promote quicker first reactions (TTFR), see Sect. 1.4 for definition. This does not include the time to hands on steering (TTHoS) which will be constant for all take-over situations.

2. A reaction to expected situations will occur quicker than to unexpected situations, so long the criticality is similar. This is because reactions towards expected situations can be planned prior to the warning itself. Expected and, therefore, anticipated take-over situations will yield no difference in reaction times.

3. Reaction times will be within a similar scope to the results obtained in the previous simulator study (Lotz et al. 2019b). The magnitude of the average time to first reaction will be under $2 \mathrm{~s}$ for highly critical take-over situations with a NDRT.

4. The engagement in the NDRT will cause the TTFR to be slower if the NDRT is not addressed.

\section{Methods}

\subsection{Participants}

A total of 27 participants were recruited through direct inquiry at 60 hauler and logistic firms. Participation was voluntary; all participants were professional truck drivers, receiving a financial incentive. Seven participants were excluded from the data analysis due to technical synchronization failures of the eye-tracker with the vehicle data and one participant mentioning discomfort driving with the 
automated function. The experiment could be terminated at any point in time and all participants gave an informed consent to the experiment. It was explained in detail that the truck was fitted with a prototypic function and warnings, which could arise at any moment in time. Physical wellbeing was addressed and queried prior to the start of the experiment and monitored during procedure. In addition, the experimental design underwent an internal audit by an ethical steering committee.

The remaining 20 participants were all male with a mean age of $\mathrm{M}=47.1$ years ( $\mathrm{SD}=12.0$ years) and reached an average annual mileage of $63,770 \mathrm{~km} /$ year $(\mathrm{SD}=38,732 \mathrm{~km} /$ year). A self-estimated $32.3 \%$ of the annual mileage was spent on highways, $42.0 \%$ were driven on overland roads, and the remaining $25.7 \%$ was driving in urban settings. In the sample of this study, one participant was not familiar with speedometers or adaptive cruise control, while over $90 \%$ used these systems daily.

\subsection{Apparatus}

\subsubsection{Vehicle}

A Mercedes-Benz Actros 1845 including a prototypic automation function enabling Level 3 on highways was provided for all drives. Controls of the automation function were identical to that of the series Active Drive Assist (Daimler 2018), on the right-hand side of the steering wheel. The automation function was engaged through the 'Set' button to the current speed and could be toggled to the desired speed through plus or minus controls. The second option of engaging the automation function was initiated through the 'Resume' button, reactivating the previously set speed, see Fig. 1. Automation could be terminated at any moment in time through the 'OFF'-button.

Once Level 3 driving was activated, the vehicle controlled the lateral and longitudinal maneuvering, kept the vehicle within lane markings, and decelerated if obstacles appeared ahead. Lateral control required the input of lane markings to a camera and a radar provided objects in the surroundings, to brake accordingly. Braking was not necessary within the experimental setting, as the truck was the slowest vehicle on the test track. All surrounding vehicles were steered by drivers with safety training.

\subsubsection{Track}

All participants were invited to the automotive testing ground in Papenburg, Germany (ATP Automotive Testing Papenburg GmbH 2018) and instructed on all safety regulations. The testing ground includes a high-speed oval with a length of $12.3 \mathrm{~km}$ and five lanes for simulated highway driving. Due to regulations on the track, the minimal driving speed was $90 \mathrm{~km} / \mathrm{h}$, which all drivers followed during the drives. The Level 3 driving was only initialized on the 4-km-long straights, while the steep curves were driven manually on the lowest lane. The study was conducted in December, which included quickly changing weather including sunshine, heavy rain, strong winds, and overcast skies.

\subsubsection{Eye-tracker}

Gaze behavior was tracked through a Smart Eye Pro eyetracker. Mounted on the dashboard, four lenses were dispersed around the driver to monitor gazes into the windscreen, onto the tablet, into the instrument cluster and towards both rear-view mirrors. The system was utilized to record the visual attention towards a non-driving-related task during procedure. The sampling rate was $60 \mathrm{~Hz}$.
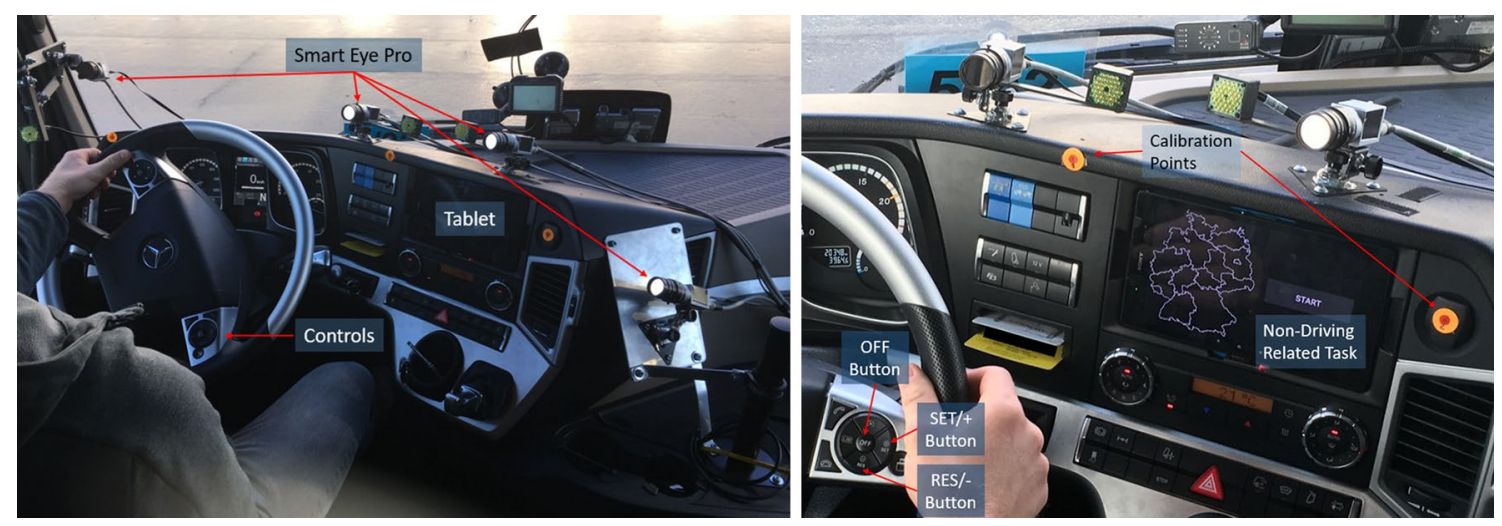

Fig. 1 (Left) Cockpit overview with Smart Eye Pro eye-tracker and mounted tablet. Right: details of automation controls on the steering wheel and the tablet providing the non-driving-related task (NDRT) 


\subsubsection{Non-driving-related tasks (NDRT)}

During activation of the automation function, interaction with NDRT was available. Participants were not encouraged to attend the NDRT, to allow them to allocate attention freely. This resulted in some drivers not attending the NDRT throughout Level 3 automation. The affected trails were handled separately during data analysis.

The NDRT was based on a previously developed interactive geography quiz (Lotz et al. 2019b). A contoured map of Germany was displayed on a mounted tablet in the central console, see Fig. 1. The task consisted of locating cities on the map by setting coordinates through touch. Chosen specifically to engage participants for longer periods and allow non-fluent speakers to interact in a quiz, this task proved as highly engaging in previous studies. To interact with the NDRT, visual and motoric attention was required. Through the new environment, the possibility of driving a highly automated vehicle, the necessity to drive manually in the curves and the novel test track environment for each participant, we are confident that passive fatigue did not occur, as discussed by Marberger et al. (2018). However, this was not controlled and will not be addressed further.

\subsubsection{Take-over situations and warnings}

Three different take-over situations were investigated in the present study with varying time criticality. In each situation type, one of two optical-acoustic warnings was presented. One possible combination was not tested; this resulted in three take-over situations: (1) yellow warning with low situation criticality, (2) red warning with low situation criticality, and (3) red warning with high situation criticality. A yellow warning was only presented at the end of a straight and red warnings could appear at any moment due to system limits being breached.
1. Yellow take-over situation: at the end of each straight, a yellow take control warning with a 10 -s countdown was displayed in the instrument cluster. The warning consisted of a periodical tone with $200 \mathrm{bpm}$ at $1200 \mathrm{~Hz}$ with a yellow icon in the instrument cluster, see (4) in Fig. 2. As Level 3 was not available in the track's steep turns, this automatic prompt was always displayed. To let the drivers accustom to the vehicle and surroundings, this warning was not displayed on Straight \#1. The reason for the yellow warning due to the steep curves was provided to all participants. The yellow warning was, therefore, repetitive and could be expected by participants. The criticality was low, as there were more than $10 \mathrm{~s}$ until the steep curve began. Participants were instructed to turn off the automation function and continue driving manually when the yellow warning was displayed throughout the complete curve and reactivate automation on the following straight.

- Yellow warning: occurring at the end of straights as an indication to regain manual control with at least 10 s headway. The vehicle continued on its trajectory with no perceivable increased criticality.

2. Red take-over situation: consisted of a red take control warning presented when the vehicle reached system limits and a continuous tone at $1200 \mathrm{~Hz}$ occurred, see (5) in Fig. 2. Participants were instructed to take back control of the vehicle as soon as possible when this signal appeared, as the system reached its limit. The red warning was presented multiple times during Level 3 activation, see Fig. 3. The automation function registered the take-over at the steering wheel upon which the warning terminated instantly. Participants did not need to deactivate the function with the 'OFF'-button. Additionally, the final yellow warning on Straight \#9 was substituted with this red take-over warning, to investigate the response towards switched warning types and,
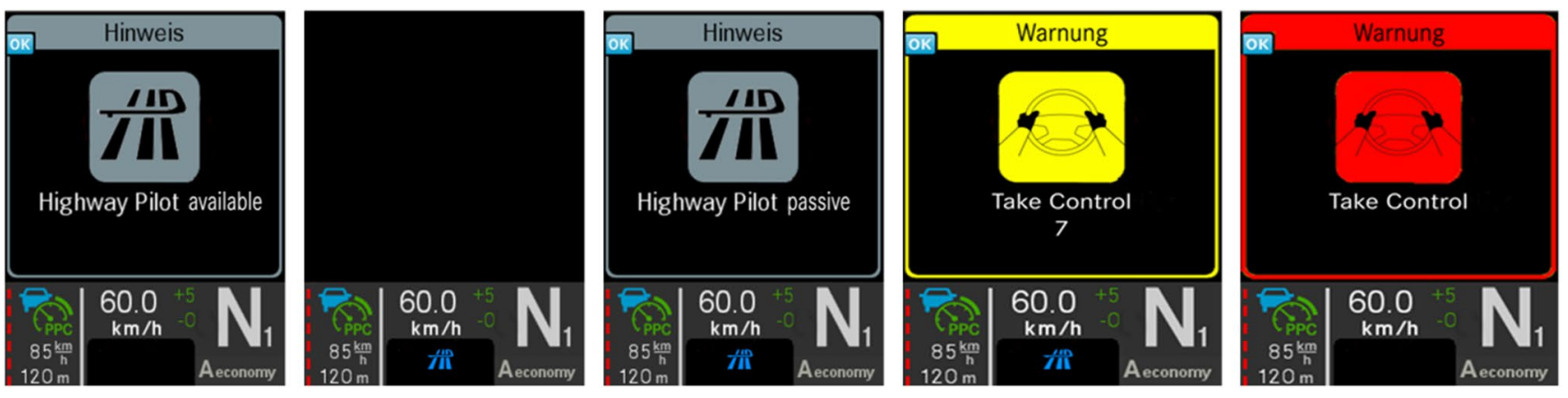

Fig. 2 Automation system warnings in the instrument cluster between speedometer and rev counter. Left to right: (1) automation available and ready for activation. (2) Automation function activated as symbolized through blue 'HP' symbol. (3) Activation function passive due to oversteering by participants. (4) Yellow warning at the end of all straights with a 10-s counter. (5) Red warning advising immediate take control (color figure online) 


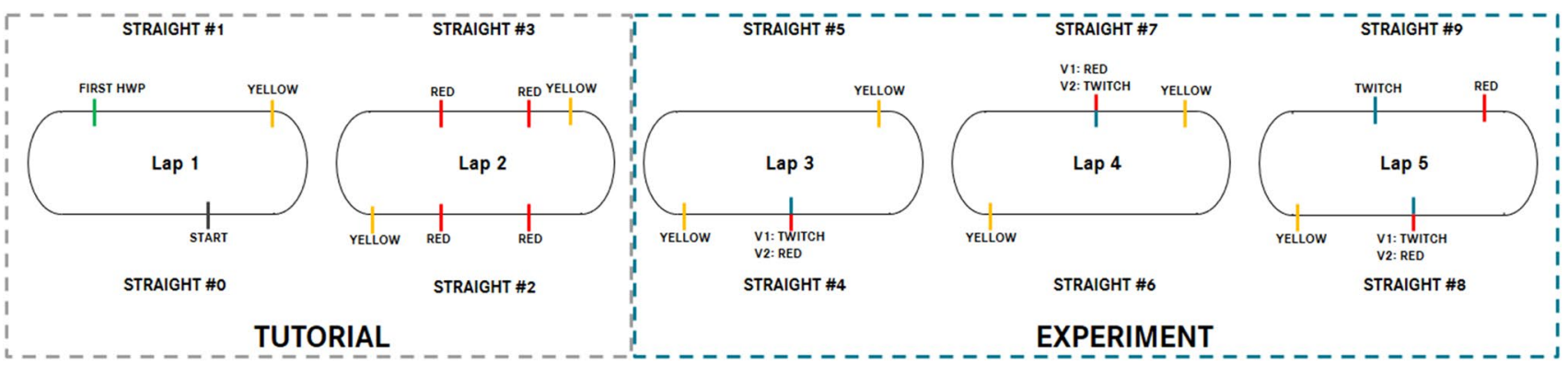

Fig. 3 Overview of the procedure of participants with the chronology of take-over types during Level 3. Three different take-over situations were presented: yellow, red and twitch (lane twitch) scenarios. The

therefore, an unexpected warning signal with identical criticality

- Red warning: occurring anywhere on the straights with the instruction to regain control as quickly as possible. The vehicle continued on its trajectory with no perceivable increased criticality.

3. Lane twitch take-over situation: instead of warning without seeming environmental reason and low criticality, a rapid trajectory change was induced to generate a takeover situation with high criticality and the red warning was displayed. This warning was only induced on the straights without the need to regain manual control immediately in front of steep curve, due to safety reasons. This take-over type is referred to as a lane twitch hereon.

- Red warning and lane twitch: occurring during automation anywhere on the straights with the instruction to regain control as quickly as possible. The vehicle trajectory changed rapidly to increase criticality.

The trajectory change induced resulted in a steering wheel angle change $\left(\mathrm{M}=18.68^{\circ}, \mathrm{SD}=2.81^{\circ}\right)$ to the right, a track offset $(\mathrm{M}=0.21 \mathrm{~m}, \mathrm{SD}=0.12 \mathrm{~m})$ and lateral acceleration $\left(\mathrm{M}=0.60 \mathrm{~m} / \mathrm{s}^{2}, \mathrm{SD}=0.25 \mathrm{~m} / \mathrm{s}^{2}\right)$. A safety engineer seated on the rear seat behind the participants observed traffic in the rear-view mirrors and did not start the take-over if vehicles were within the proximity.

\subsection{Procedure}

After completing all safety introductions participants filled out a socio-demographic questionnaire, the automation function and NDRT were described and one lap on the test track as a passenger was completed. During all drives, one safety engineer was present in the vehicle and an additional experimenter guided the participants through the tutorial and drive. During the introductory lap, the automation function was not shown; however, the controls were clarified at the steering wheel and function-related questions were answered. The participants had no specific instructions for the drive other procedure was completely identical except for the take-over situations on Straight \#4, \#7 and \#8 in which each driver drove either variant V1 or V2 (color figure online)

than to experience a prototypic automation function novices but with a professional background and high driving experience.

Participants were in control of the vehicle for five laps (Straight \#0-\#9), of which the first two laps consisted of a guided tutorial to accustom to the automation function. The automation function was initiated on Straight \#1 for the first time, see Fig. 3. Drivers could overrule the function at any time by pressing the ac-/decelerator pedals or guiding the vehicle laterally with the steering wheel without turning the automation function off, see (3) in Fig. 2. While the automation function was being overruled, the function was passive and reinitiated itself upon terminating the overruling. During the first four straights, the participants experienced a total of seven take-overs (three yellow, four red), see Fig. 3. The first red take-over warning on each straight during the tutorial phase was always announced prior to the take-over. On Straight \#3, the NDRT was activated the first time and the red warning symbol was displayed on the tablet during the request to intervene. The yellow take-over situation was announced in the tutorial phase to accustom participants to turn off the Level 3 automation when approaching the steep curves.

The actual experiment phase began with the approach onto Straight \#4. The participants drove one of two scenarios in the experiment phase in which the red and lane twitch take-overs on Straight \#4, \#7 and \#8 were reversed, see Fig. 3. The reversal of the two scenarios was aimed at investigating the influence of the tutorial phase on known take-over scenarios, red take-over, and unknown critical take-overs, lane twitch, directly after the tutorial phase. The order of the time critical take-overs is depicted in Fig. 3 for both scenarios (V1 and V2). The participants activated the automation function at the beginning of each straight and the NDRT was unlocked. The five laps were completed within approximately $45 \mathrm{~min}$. Due to the fact that sunset was at $16: 15$ (4:15 pm); it was possible to collect data in the early phases of night as two drives started after 16:30 (4:30 pm) each day. 


\section{Results}

The study design is a within-subject design with repeated measures resulting in 356 take-overs. The vehicle data, eye-tracking and video recordings were synchronised and analyzed with respect to the formulated hypotheses of Sect. 1.5. Due to the fact that the prototypic vehicle was not fitted with a capacitive steering wheel, the time to hands on steering (TTHoS) were evaluated from a synchronised video of the drives. For the time to first reaction (TTFR), the threshold of $1 \mathrm{Nm}$ at the steering wheel or $5 \%$ ac- or decelerator pedal position change was defined.

Figure 4 depicts TTFR for both phases of the drive (tutorial/experimental) for each take-over situation type, when drivers had their hands off the steering wheel. For the experimental phase, all reaction times are documented in Table 1. On average during the experiment phase, this resulted in a TTFR $(\mathrm{M}=1.087 \mathrm{~s}, \mathrm{SD}=0.417 \mathrm{~s})$, TTHoS $(\mathrm{M}=0.727 \mathrm{~s}, \mathrm{SD}=0.253 \mathrm{~s})$, and TTEoR $(\mathrm{M}=0.364 \mathrm{~s}$, $\mathrm{SD}=0.425 \mathrm{~s}$ ) for a total of 162 take-overs in which the

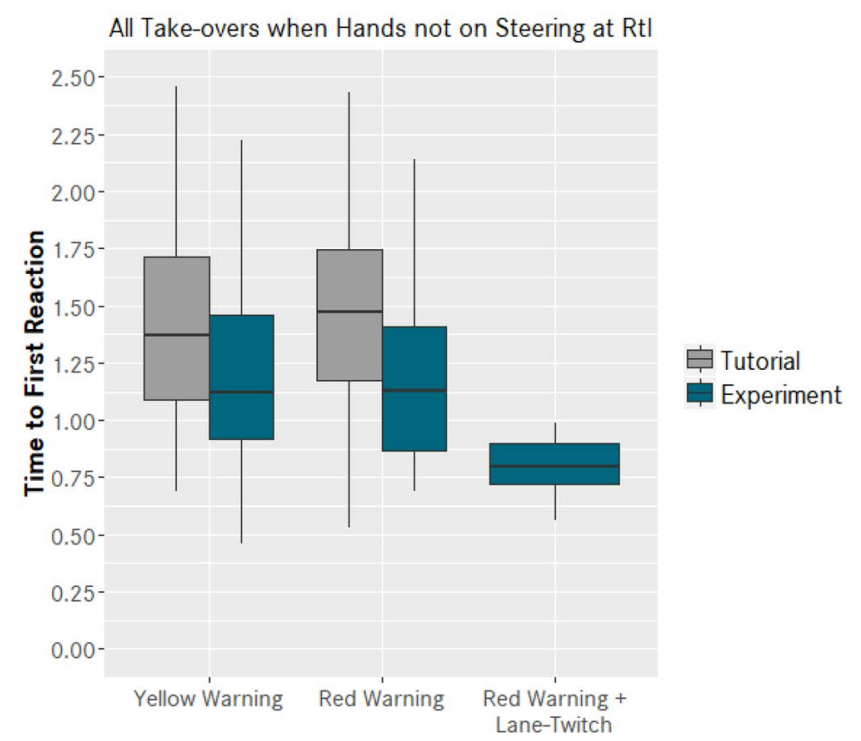

Fig. 4 Left: time to first reaction (TTFR) in the tutorial and experimental phase when hands were not guiding the steering wheel for each different warning type (i.e., yellow, red and red, and lane- hands were off the steering. An analysis of all take-overs through a full factorial ANOVA with factor phase (tutorial, experiment), situation type (yellow, red, lane twitch), hands on steering (true, false), and daytime (day, night) was conducted for TTFR and TTHoS. The results of both ANOVA are presented in Table 2. An overview of the quickest and slowest reaction times is also given in Table 1. For some considered take-over situations of situation type yellow and red, TTEoR and TTFR of $0 \mathrm{~s}$ were recorded. This displays take-over situations in which the driver had their eyes on the road and was not engaging in the secondary task. For the yellow situation types this TTEoR was $0 \mathrm{~s}$ in 33 take-overs, while in the red situation types this only occurred once, displaying anticipation of a take-over situation. Even the maximal outliers display very quick reaction times for all take-over situations. Notably, the maximum TTEoR are slower than TTFR and TTHoS. This can be attributed to drivers focusing on the instrument cluster with the hands already being placed on the steering. The analysis of both the TTFR and TTHoS portrays that there is a significant effect of drive phase in

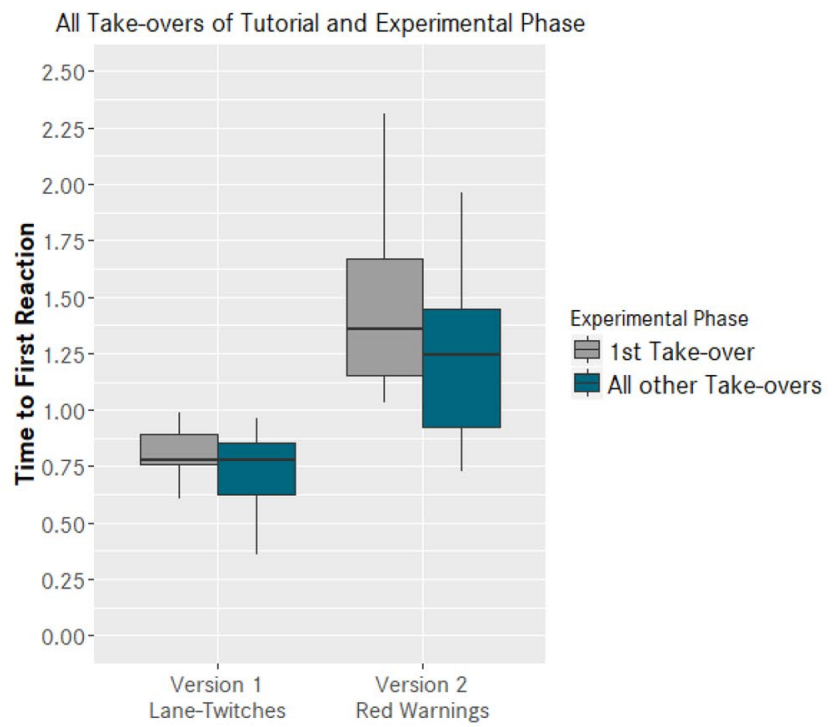

twitch). Right: time to first reaction (TTFR) for the two different versions with respect to the first take-over compared to all other takeovers of the same situation type (color figure online)

Table 1 Time to first reaction, time to hands on steering and eyes on road in experiment phase

\begin{tabular}{|c|c|c|c|c|c|c|c|c|c|c|}
\hline \multirow[t]{2}{*}{ Situation type } & \multirow[t]{2}{*}{ \# of take-overs } & \multicolumn{3}{|c|}{ Time to first reaction (s) } & \multicolumn{3}{|c|}{ Time to hands on steering (s) } & \multicolumn{3}{|c|}{ Time to eyes on road (s) } \\
\hline & & Min & $\operatorname{Max}$ & Avg & Min & Max & Avg & Min & Max & Avg \\
\hline Yellow & 67 & 0 & 2.31 & $\mathrm{M}=1.222(\mathrm{SD}=0.403)$ & 0.06 & 1.65 & $\mathrm{M}=0.705(\mathrm{SD}=0.300)$ & 0 & 2.28 & $\mathrm{M}=0.324(\mathrm{SD}=0.449)$ \\
\hline Red & 53 & 0 & 2.31 & $\mathrm{M}=1.109(\mathrm{SD}=0.469)$ & 0.36 & 1.56 & $\mathrm{M}=0.772(\mathrm{SD}=0.244)$ & 0 & 2.01 & $\mathrm{M}=0.496(\mathrm{SD}=0.469)$ \\
\hline Lane Twitch & 42 & 0.36 & 1.58 & $\mathrm{M}=0.841(\mathrm{SD}=0.233)$ & 0.36 & 1.56 & $\mathrm{M}=0.705(\mathrm{SD}=0.173)$ & 0 & 0.78 & $M=0.262(S D=0.267)$ \\
\hline
\end{tabular}

Minimum, maximum, and average times are reported 
Table 2 Results of full-factorial ANOVA for TTFR and TTHoS

\begin{tabular}{|c|c|c|c|c|c|c|c|}
\hline Dependent variable & Measure & Sum of squares & $d \mathrm{f}$ & Mean square & $F$ & $\operatorname{Pr}(>F)$ & Partial $\eta^{2}$ \\
\hline \multirow[t]{18}{*}{ Time to first reaction } & Phase & 12.59 & 1 & 12.59 & 43.43 & $1.69 e-10$ & 0.114167 \\
\hline & Expectancy & 0.93 & 1 & 0.93 & 3.203 & 0.07441 & 0.009414 \\
\hline & Criticality & 2.60 & 1 & 2.60 & 8.974 & 0.00294 & 0.025939 \\
\hline & Hands on steering & 34.91 & 1 & 34.91 & 120.5 & $<2 \mathrm{e} 16$ & 0.263357 \\
\hline & Daytime & 0.00 & 1 & 0.00 & 0.016 & 0.90028 & 0.000047 \\
\hline & Phase $*$ expectancy & 0.08 & 1 & 0.08 & 0.280 & 0.59711 & 0.000830 \\
\hline & Phase * hands on steering & 3.15 & 1 & 3.15 & 10.87 & 0.00108 & 0.031260 \\
\hline & Expectancy * hands on steering & 2.16 & 1 & 2.16 & 7.441 & 0.00671 & 0.021603 \\
\hline & Criticality $*$ hands on steering & 0.03 & 1 & 0.03 & 0.106 & 0.74553 & 0.000313 \\
\hline & Phase * daytime & 0.29 & 1 & 0.29 & 0.998 & 0.31843 & 0.002954 \\
\hline & Expectancy $*$ Daytime & 0.22 & 1 & 0.22 & 0.752 & 0.386601 & 0.002252 \\
\hline & Criticality * Daytime & 0.00 & 1 & 0.00 & 0.000 & 0.98561 & $9.67 e-07$ \\
\hline & Hands on steering * daytime & 3.84 & 1 & 3.84 & 13.25 & 0.00032 & 0.037824 \\
\hline & Phase $*$ expectancy $*$ hands on steering & 0.04 & 1 & 0.04 & 0.135 & 0.71391 & 0.000399 \\
\hline & Phase $*$ expectancy $*$ daytime & 0.00 & 1 & 0.00 & 0.006 & 0.93690 & 0.000019 \\
\hline & Phase $*$ hands on steering $*$ daytime & 0.36 & 1 & 0.36 & 1.243 & 0.26563 & 0.003676 \\
\hline & Expectancy $*$ hands on steering $*$ daytime & 0.21 & 1 & 0.21 & 0.716 & 0.39822 & 0.002119 \\
\hline & Phase * expectancy * hands on S.* daytime & 0.00 & 1 & 0.00 & 0.000 & 0.99852 & $1.02 \mathrm{e}-08$ \\
\hline \multirow[t]{18}{*}{ Time to hands on steering } & Phase & 1.288 & 1 & 1.288 & 19.985 & $1.07 e-05$ & 0.055982 \\
\hline & Expectancy & 4.509 & 1 & 4.509 & 69.968 & $1.62 e-15$ & 0.171925 \\
\hline & Criticality & 0.013 & 1 & 0.013 & 0.204 & 0.6517 & 0.000605 \\
\hline & Hands on steering & 27.29 & 1 & 27.29 & 423.51 & $<2 \mathrm{e}-16$ & 0.556880 \\
\hline & Daytime & 0.339 & 1 & 0.339 & 5.260 & 0.0224 & 0.015368 \\
\hline & Phase $*$ expectancy & 0.015 & 1 & 0.015 & 0.226 & 0.6347 & 0.000671 \\
\hline & Phase * hands on steering & 0.156 & 1 & 0.156 & 2.414 & 0.1212 & 0.007113 \\
\hline & Expectancy $*$ hands on steering & 0.028 & 1 & 0.019 & 0.295 & 0.5132 & 0.001270 \\
\hline & Criticality $*$ hands on steering & 0.010 & 1 & 0.010 & 0.162 & 0.6877 & 0.000480 \\
\hline & Phase * daytime & 0.003 & 1 & 0.003 & 0.040 & 0.8418 & 0.000118 \\
\hline & Expectancy $*$ daytime & 0.009 & 1 & 0.009 & 0.143 & 0.7052 & 0.000425 \\
\hline & Criticality $*$ daytime & 0.000 & 1 & 0.000 & 0.005 & 0.9463 & 0.000014 \\
\hline & Hands on steering $*$ daytime & 0.062 & 1 & 0.062 & 0.956 & 0.3289 & 0.002828 \\
\hline & Phase $*$ expectancy $*$ hands on steering & 0.000 & 1 & 0.000 & 0.000 & 0.9988 & $7.04 \mathrm{e}-09$ \\
\hline & Phase $*$ expectancy $*$ daytime & 0.028 & 1 & 0.028 & 0.439 & 0.5082 & 0.001300 \\
\hline & Phase $*$ hands on steering $*$ daytime & 0.001 & 1 & 0.001 & 0.012 & 0.9144 & 0.000034 \\
\hline & Expectancy $*$ hands on steering $*$ daytime & 0.001 & 1 & 0.001 & 0.011 & 0.9153 & 0.000034 \\
\hline & Phase * expectancy * hands on S.* Daytime & 0.004 & 1 & 0.001 & 0.056 & 0.8137 & 0.000165 \\
\hline
\end{tabular}

the data, this is to be expected as drivers were instructed and novices in the tutorial phase. If the hands of the driver were on the steering, this resulted in a highly significant main effect for both reaction times. A small effect is registered for the factor criticality (yellow/red vs. lane twitch), while the expectancy (yellow vs. red) yielded no effect for TTFR. Three further mild interaction effects were identified for TTFR. These results lead to a rejection of Hypothesis \#1, as no clear indication of expectancy and criticality is identified for TTFR. Contrarily, a highly significant main effect for expectancy (yellow vs. red warning) was identified for TTHoS, while the data did not display any significant differences for criticality, see Table 2 .

As participants drove one of two versions, see Sect. 2.3, a version comparison was conducted for the first takeovers in comparison to all other take-overs in the experimental phase. The comparison aims to identify whether the novel situation lane-twich $(\mathrm{M}=0.807, \mathrm{SD}=0.118)$ caused prolonged TTFR compared to all other lanetwitches $(M=0.725, S D=0.340)$, see Fig. 4. As the red warning was learned in the tutorial phase participants were familiar with this situation type. Due to unequal sample 
size homoscedasticity was tested through a levene test with factors situation type and the binary factor first take-over or all others for the dependent variable TTFR. As homoscedasticity was not achieved $\mathrm{F}(3,65)=2.63, p=0.058$, a Welch test was performed displaying significance only for situation type $\mathrm{F}(1,65)=17.617, p<<0.001$. The results display no difference with respect to first appearance of take-over situations, showing that the highly critical lane twitch situation was attended unconditional of novelty. With respect to the red situation type, non-significant results strengthen the assumption that learning of takeover procedure in the tutorial phase was effective.

Similarly, on the last straight of the experimental phase (Straight \#9), drivers experienced a different expected warning, a red take-over warning was displayed instead of a yellow warning. Figure 5 (left) depicts the TTFR for all yellow warnings on Straight \#8 compared to the novel red warning at the end of Straight \#9. A two-way ANOVA for TTFR was calculated with the categorical variable whether hands were touching the steering or not and the situation type. This resulted in a significant effect for hands on steering $\mathrm{F}(1,36)=18.67, p=0.0002$, partial $-\eta^{2}=0.329$, but not for situation type $\mathrm{F}(1,36)=0.349$, $p=0.558$, partial $-\eta^{2}=0.0091$.

Also in Fig. 5 (right), TTFR is presented for the three different situation types and whether participants engaged in the NDRT within $2 \mathrm{~s}$ prior to RtI. Engagement was determined through eye-tracking data and if the tablet was touched within this timeframe. A one-way ANOVA for NDRT engagement was calculated for TTFR with no significant effect, $\mathrm{F}(1,162)=0.004, p=0.948$, partial- $\eta^{2}=0.00002$.

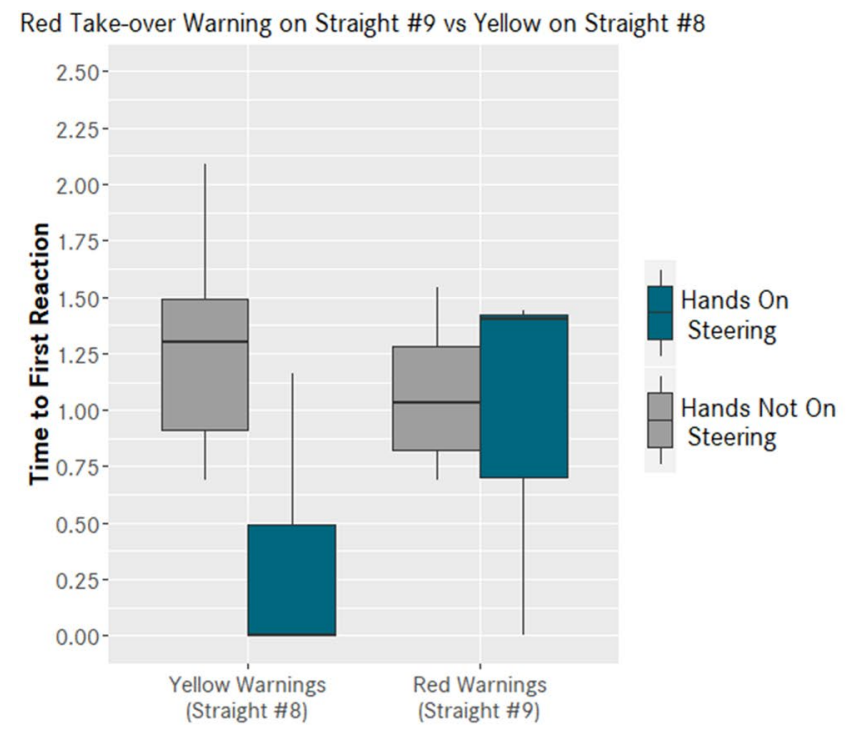

\section{Discussion}

Multiple research questions are addressed in the present study concerning take-over behavior of professional truck drivers in Level 3 automation. Test track drives, simulating highway scenarios, with non-affiliated professional truck drivers were investigated to identify reactions towards different warning types and criticalities resulting in take-over situations. The information gathered is paramount to design future driver assistance systems, enhance usefulness (DIN EN ISO 9241-210:2010 2010) and apply a human-centered design approach (Cooley 1982). A positive byproduct of applying this knowledge to the design process of future systems is to achieve the goal of reducing workload on drivers and therein decrease accidents.

\subsection{Take-over criticality}

One of the prime focuses of this study was to identify driver behavior for varying critical take-over situations in a real vehicle. The statistical analysis of TTFR displayed a mildly significant effect of the two levels of take-over criticality, while TTHoS was constant for this factor. Criticality was manipulated by inducing a steering impulse in the high condition, causing the steering wheel to swerve to the right when drivers were occupied with a NDRT and hands were not on the steering wheel. However, no visual obstacles caused the variation in criticality to bypass any risk of causing an accident for the participants. Driver interaction depending on criticality seems to cause a quicker first reaction at the controls of the vehicle, see Fig. 4. However,

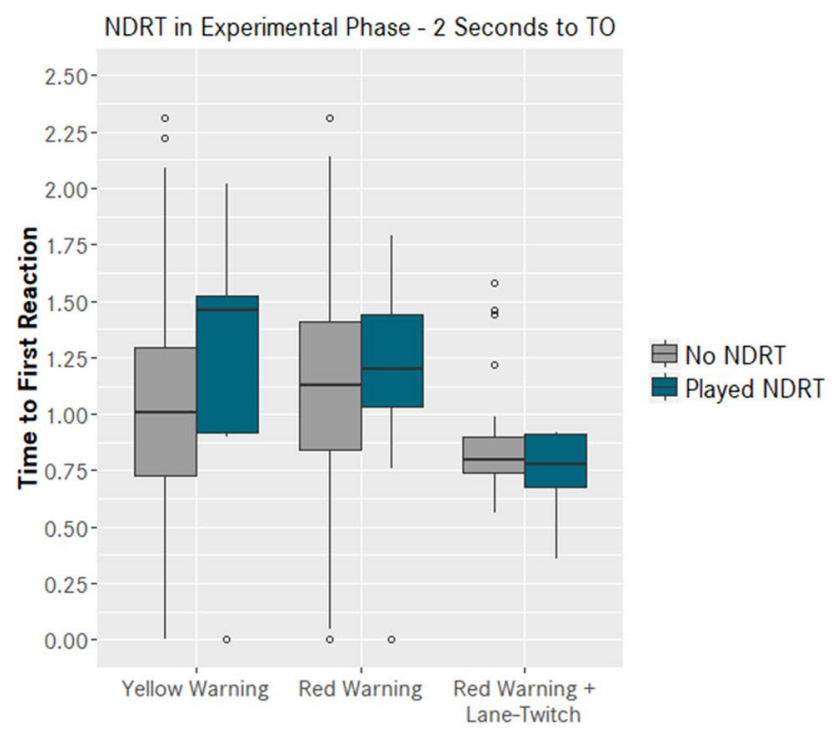

Fig. 5 Left: time to first reaction (TTFR) for all expected yellow warning and expected red warning on Straight \#9. Right: comparison of TTFR for all warning types and whether NDRT was played or not within $2 \mathrm{~s}$ prior to a take-over request (color figure online) 
this does not signify that route planning for the handling of the situation was quicker. The lane twitch situation in this study caused an acceleration to be perceived by the driver. Instinctive reaction to the kinaesthesia could have caused the quicker time to first reaction. Hypothesis 1 is therefore failed to be rejected, with necessary future investigations focusing on the causation of quicker reactions.

\subsection{Warning expectancy}

Two different warning types were presented in the three different take-over situations. The two take-over warnings consisted of a yellow take control warning issued solely at the end of a straight and a red take control warning issued when system limits were met and drivers had to regain control immediately. These two take-over situations did not differ in criticality and were issued on the straights. In these situations, the system did not appear to mishandle the driving task; however, take-over was required (yellow and red). A yellow take-over warning was always presented at the end of a straight, allowing each participant to foresee (expect) this combination of situation type and warning when approaching the steep curve. Solely on the last straight, the yellow warning was replaced with a red warning.

The comparison of the red and yellow warnings displayed no significant difference for TTFR. Interestingly, a highly significant effect for expectancy was identified for TTHoS. As the yellow warning could be expected at the end of the straights, take-over procedure could be anticipated at the end of the straights. This is also present in the data, as at roughly $50 \%$ of all yellow take-over situations, the eyes were already focused on the road, demonstrating expectancy. The overall tendency of expectancy to have no effect on TTFR was also identified for the first and last take-overs in the experiment phase in which new and switched warnings were presented, respectively. The discrepancy between TTFR and TTHoS regarding expectancy can have multiple reasons. However, primarily only placing the hands at the steering caused the warning to terminate. The effect of expectancy on TTHoS is, therefore, anticipated. As a clear driver interaction based on obverting an obstacle at take-over was not necessary, the threshold for TTFR could have been set too high for the reaction to register similar to TTHoS.

An analysis of the final take-over warning at the end of Straight \#9, which was switched from an expected yellow warning to a red warning, produced no significant effect for TTFR. However, reaction times did differ significantly in the yellow warning situation when hands were guiding the steering. A probable explanation is that some participants expected yellow warnings, while others trusted the automation function to warn them adequately possibly also verifying the warning in the instrument cluster. With the appearance of a different auditory-visual, warning was expected; however, the criticality was not and led to a reevaluation of the situation. The motoric response to unforeseeable takeovers did not differ throughout the drives and averaged at $0.727 \mathrm{~s}$. A similar conclusion was drawn when explicitly investigating the hands-off times in partially automated traffic jam scenarios with critical take-over situations (Naujoks et al. 2015). Therefore, based on the information gathered, Hypothesis \#2 is failed to be rejected.

\subsection{Comparability to simulator studies}

Another research focus is to compare previously gathered information in a moving-base simulator to driver behavior in a real vehicle. Generally, current investigations in the Level 3 context are examined exclusively in simulators, to exclude the possibility of technical malfunctions or human error causing accidents. This is mainly because prototypes often are not as sophisticated as series technology and novel or extreme situations are investigated. While the possibilities in simulated environments have excelled in recent years, unexpected influences might take an effect on results when trying to extrapolate results to a real-world context. Such influences could include the intrinsic trust of participants that no direct physical harm will occur in a simulator and the aspect of treating driving simulators as games (Bellem et al. 2016). Overall, results obtained in simulators have to be validated in controlled and safe real-world scenarios to manifest conclusions drawn from the data. As previous experimental results in a truck simulator produced extremely quick TTFR $(\mathrm{M}=1.35, \mathrm{SD}=0.49)$ for 755 highly time-critical take-overs (Lotz et al. 2019b), it was our motivation to validate these findings.

Results in Sect. 3 show that especially the motoric response time, TTHoS, was constant regardless the expected criticality. Learning was observed from the tutorial to the experimental phase, see Fig. 4. The TTFR reduced significantly between the tutorial and experimental phase generating consistent results of learning behavior as observed previously (Lotz et al. 2019b). These near-constant motoric response times observed in the data cohere with the findings from Zeeb et al. (2015). Second, the different warning types yielded a significant effect for TTHoS in the experimental phase. This contradicts the results for TTFR, as only the most critical take-over situation generated a mildly significant decreased reaction time. Overall, a TTFR of $1.08 \mathrm{~s}$ was observed for all take-over situations in which the hands were not guiding the steering wheel. A separate investigation of TTFR for NDRT engagement yielded no significant results.

For the consideration of reaction times in the present study the results of the descriptive and inferential analysis fail to reject Hypothesis 3 with a $3 \sigma$-interval of 0-2.343 s for 164 take-overs, depicting $99.7 \%$ of the data. One drawback and possible explanation of the difference in TTFR could 
be the low torque required to take-over the vehicle in the yellow and red warning conditions. Only in the lane-twitch condition was a strong steering wheel torque required. It should be noted that the present study did not present highly time critical situations due to environmental obstacles, but the steering was manipulated in the lane-twitch condition to induce criticality as a safe option to investigate take-over criticality.

\subsection{Non-driving-related tasks (NDRT)}

Multiple publications investigation the effect of NDRT during Level 3 have been published recently (Merat et al. 2012; Petermann-Stock et al. 2013). In the present study participants could engage in a NDRT during Level 3 automation. As a measure of engagement the visual attention towards the NDRT and tablet interaction were consulted, see Fig. 5. The data reported shows no significant effect of NDRT on TTFR. This is unexpected and leads to a rejection of Hypothesis 4. While the results in published research show no significant effects amongst different NDRT (Radlmayr et al. 2014), a general negative effect of tasks is documented (Vogelpohl et al. 2016). In the present study, participants could choose freely if they wanted to attend the NDRT or not. It is possible that the self-motivated engagement was, therefore, lower than in studies in which direct task instruction was provided.

\section{Conclusion}

With little experience to lean on, as no studies addressing a standardized procedure of investigating take-over behavior in critical take-over situations exists, this study presents novel insights into the experimental procedure and results of near real-world take-over behavior for Level 3. A total of 292 take-overs in which hands were not guiding the steering wheel and 64 with hands on steering were examined. The information gathered allows for a better understanding of reaction times and behavior during take-overs to expected and unexpected events. Ultimately, this is valuable knowledge to reduce accidents in critical take-over situations in which the machine and humans share responsibility of guiding vehicles safely. For optimal data comparability, we would welcome a definition of take-over situations and measures throughout the community.

Compared to previous results, the reaction times are in the lower spectrum of reported reaction times (Eriksson et al. 2017). As argued previously, professional truck drivers form a unique sample as experience and training are high. It should be clear, however, that no driver had previously driven on this test track, the automation function and vehicle was uncommon and drivers were inclined to act safely. The time to first reaction $(\mathrm{M}=1.087 \mathrm{~s}, \mathrm{SD}=0.417 \mathrm{~s})$, time to hands on steering $(\mathrm{M}=0.727 \mathrm{~s}, \mathrm{SD}=0.253 \mathrm{~s})$ and time to eyes on road $(\mathrm{M}=0.364 \mathrm{~s}, \mathrm{SD}=0.425 \mathrm{~s})$ are most likely as quick as possible for the presented scenarios.

As no obstacles were manipulated in the environment of the vehicles at take-over, the reaction times only display the cognitive and motoric response times required to react towards a take-over signal. Resulting trajectories or displacements within the lane were not investigated. Primarily due to short distances on the test track straights and as participants reactivated the automation function within $10 \mathrm{~s}$, an analysis of take-over quality is absent. In conclusion, the collected reaction times present the quicker spectrum of take-over capability by professional truck drivers. While the limit of take-over reaction times cannot be much quicker, slower reaction times due to long automation phases, higher distraction and repetition are very likely and need thorough investigation in the future. The reaction times here present the minimum time an automation function needs to span to assist driver take-over behavior. This still disregards if the driver feels comfortable with these take-over times and is capable of delivering this high performance over longer periods of time.

Acknowledgments Open Access funding provided by Projekt DEAL.

\section{Compliance with ethical standards}

Conflict of interest Alexander Lotz and Enrico Wohlfarth are employed by Daimler AG.

Open Access This article is licensed under a Creative Commons Attribution 4.0 International License, which permits use, sharing, adaptation, distribution and reproduction in any medium or format, as long as you give appropriate credit to the original author(s) and the source, provide a link to the Creative Commons licence, and indicate if changes were made. The images or other third party material in this article are included in the article's Creative Commons licence, unless indicated otherwise in a credit line to the material. If material is not included in the article's Creative Commons licence and your intended use is not permitted by statutory regulation or exceeds the permitted use, you will need to obtain permission directly from the copyright holder. To view a copy of this licence, visit http://creativecommons.org/licenses/by/4.0/.

\section{References}

ATP Automotive Testing Papenburg GmbH (2018) Automotive Testing Papenburg. Citation: 20.02.2019 https://atp-papenburg.de

Audi (2017) Audi Technology Portal. Citation: 26.02.2019 from Audi A8 - Audi AI traffic jam pilot: https://www.audi-technology-porta 1.de/en/electrics-electronics/driver-assistant-systems/audi-a8audi-ai-traffic-jam-pilot

Axelson M, Ahlström C, Krupenia S, Anund A, Leeuwen W, Kecklund $\mathrm{G}$ (2018) Is it possible to adjust the driving and resting times when operating highly autonomous trucks? J Sleep Res 27(1):P345

Bainbridge L (1983) Ironies of automation. Automatica 6:775-779 
Bellem H, Kluver M, Schrauf M, Schoner H-P, Hecht H, Krems JF (2016) Can we study autonomous driving comfort in movingbase driving simulators? A validation study. Hum Factors 59(3):442-456

Brookhuis K, de Waard D, Janssen W (2001) Behavioural impacts of advanced driver assistance systems - an overview. Eur J Transp Infrastruct Res 1(3):245-253

Cooley M (1982) Achitect or Bee?: Human Price of Technology (Current affairs). Chatto \& Windus, UK

Daimler (2018) Mercedes-Benz. Citation: 26.08.2019 from The new Actros 2019: https://www.mercedes-benz.com/en/mercedes-benz/ vehicles/trucks/the-new-actros-2019/

Damböck D (2013) Automationseffekte im Fahrzeug - von der Reaktion zur Übernahme. Technische Universität München, Lehrstuhl für Ergonomie, München

de Winter JC, Happee R, Martens MH, Stanton NA (2014) Effects of adaptive cruise control and highly automated driving on workload and situation awareness: A review of the empirical evidence. Transp Res Part F 27:196-217

Diederichs F, Bischoff S, Reilhac P (2015) Welchen Einfluss hat das HMI?. Vergleich von Übergabezeiten in Notfallsituationen bei SAE Level 2 und 3 Automatisierung mit neuartiger SmartphoneIntegration im direkten Fahrersichtfeld und mit Lenkradbedienung. Berliner Werkstatt Mensch-Maschine-Systeme: Trends in Neuroergonomics 11:72-79

DIN EN ISO 9241-210:2010 (2010) Ergonomics of human-system interaction Part 210: Human-centred design for interactive systems

Endsley MR (1995) Toward a Theory of situation awareness in dynamic systems. Hum Factors J 37(1):32-64

Eriksson A, Stanton NA (2017) Take-over time in highly automated vehicles: non-critical transitions to and from manual control. Hum Factors. https://doi.org/10.1177/0018720816685832

Gold C, Damböck D, Lorenz L, Bengler K (2013) Take over! How long does it take to get the driver back into the loop? Proc Hum Factors Ergono Soc Annu Meet I 57:1938-1942

Hergeth S, Lorenz L, Krems JF (2016) Prior Familiarization with takeover requests affects drivers' takeover performance and automation trust. Hum Factors J Hum Factors Ergonom Soc 59(3):457-470

Kantowitz BH, Roediger HL, Elmes DG (2009) Research techniques: experiments. Wadsworth Cengage Learning, Belmont

Lees MN, Lee JD (2007) The influence of distraction and driving context on driver response to imperfect collision warning systems. Ergonomics 8:1264-1286

Lotz A, Weissenberger S (2019) Predicting take-over times of truck drivers in conditional autonomous driving. In: Stanton N (ed) Advances in human aspects of transportation. AHFE 2018. Advances in intelligent systems and computing, vol 786. Springer, Cham, pp 329-338

Lotz A, Russwinkel N, Wohlfarth E (2019) Response times and gaze behavior of truck drivers in time critical conditional automated driving take-overs. Transp Res Part F 64:532-551. https://doi. org/10.1016/j.trf.2019.06.008

Marberger C, Mielenz H, Naujoks F, Radlmayr J, Bengler K, Wandtner B (2018) Understanding and applying the concepf of "driver availability" in automated driving. In: Stantion NA (ed) Advances in human aspects of transportation. AHFE 2017. Advances in intelligent systems and computing, vol 597. Springer, Cham
McDonald AD, Alambeigi H, Engström J, Markkula G, Vogelpohl T, Dunne J, Yuma N (2019) Towards computational simulations of behavior during automated driving take-overs: a review of the empirical and modeling literatures. Hum Factors 61:642-688

Melcher V, Rauh S, Diederichs F, Widlroither H, Bauer W (2015) Take-over requests for automated driving. 6th international conference on applied human factors and ergonomics. Procedia Manuf 3:2867-2873

Merat N, Jamson H, Lai F, Carsten O (2012) Highly automated driving, secondary task performance, and driver state. Hum Factors J Hum Factors Ergonom Soc 54(4):762-771

Naujoks F, Purucker C, Neukum A, Wolter S, Steiger R (2015) Controllability of partially automated driving functions-does it matter whether drivers are allowed to take their hands off the steering wheel? Transp Res Part F Traffic Psychol Behav 35:185-198

Petermann-Stock I, Hackenberg L, Muhr T, Mergl C (2013) Wie lange braucht der Fahrer-eine Analyse zu Übernahmezeiten aus verschiedenen Nebentätigkeiten während einer hochautomatisierten Staufahrt. 6. Tagung Fahrerassistenzsysteme. Der Weg zum automatischen Fahren

Radlmayr J, Gold C, Lorenz L, Farid M, Bengler K (2014) How traffic situations and non-driving related tasks affect the take-over quality in highly automated driving. Proc Hum Factors Ergonom Soc Ann Meet 58:2063-2067

Ruscio D, Ciceri MR, Biassoni F (2015) How does a collision warning system shape driver's brake response time? The influence of expectancy and automation complacency on real-life emergency braking. Accid Anal Prev 77:72-81

SAE J3016 (2018) from https://www.sae.org/misc/pdfs/automated_ driving.pdf

Tesla (2019) Citation: 26.02.2019 from Tesla Autopilot https://www. tesla.com/de_DE/autopilot

Vogelpohl T, Vollrath M, Kühn M, Hummel T, Gehlert T (2016) Übergabe von hochautomatisiertem Fahren zu manueller Steuerung. Gesamtverband der Deutschen Versicherungswirtschaft e.V, Berlin

Wylie G, Allport A (2000) Task switching and the measurement of "switch costs". Psychol Res 3(4):212-233

Young M, Stanton N (2002) Malleable attention resources theory: a new explanation for the effects of mental underload on performance. Hum Factors 3:365-375

Young M, Stanton N (2007) Back to the future: brake reaction times for manual and automated vehicles. Ergonomics 1:46-58

Zeeb K, Buchner A, Schrauf M (2015) What determines the take-over time? An integrated model approach of driver take-over after automated driving. Accid Anal Prev 78:212-221

Zhang B, Wilschut E, Willemsen D, Martens M (2017) Driver response times when resuming manual control from highly automated driving in truck platooning scenarios. Conference: RSS2017 Road Safety \& Simulation international conference (The Hague, Netherlands). https://doi.org/10.13140/RG.2.2.28249.01127

Publisher's Note Springer Nature remains neutral with regard to jurisdictional claims in published maps and institutional affiliations. 